\title{
Preparation and characterization of cellulose and microcrystalline cellulose isolated from waste Leucaena leucocephala seeds
}

\author{
Maryam Husin ${ }^{1,2}$, Abd Rashid Li ${ }^{3}$, Norfadhilah Ramli ${ }^{2}$, Ahmad Zafir Romli ${ }^{4}$, Mohd Idham Hakimi ${ }^{2}$, Zul Ilham $^{2, *}$ \\ ${ }^{1}$ Faculty of Applied Science, Universiti Teknologi MARA, 44050 Shah Alam, Selangor, Malaysia \\ 2Institute of Biological Sciences, Faculty of Science, University of Malaya, 50603 Kuala Lumpur, Malaysia \\ 3 Phytochemistry Program, Natural Products Division, Forest Research Institute Malaysia, 52109 Kepong, Selangor, Malaysia \\ ${ }^{4}$ Institute of Science, Universiti Teknologi MARA, 44050 Shah Alam Selangor, Malaysia
}

\section{A RTICLE INFO}

\section{Article history:}

Received 3 November 2016

Received in revised form

6 January 2017

Accepted 8 January 2017

\section{Keywords:}

Waste Leucaena leucocephala seeds

Agricultural residues

Cellulose

Lignocellulosic

Biomass

\begin{abstract}
A B S T R A C T
Cellulose and microcrystalline cellulose (MCC) were isolated from waste Leucaena leucocephala seeds (LLS) by using acid hydrolysis method. Waste LLS are unused residues after extraction of oil for conversion to biodiesel. Cellulose from LLS (LLS-cellulose) has been isolated by using $80 \%$ acetic acid and $65 \%$ nitric acid to yield 33\% cellulose. MCC was further prepared from the LLS-cellulose via the acid hydrolysis method and yield $71 \%$. The obtained LLS-cellulose and LLS-MCC samples were comparatively investigated by Fourier transform infrared spectroscopy (FTIR), Thermogravimetric analysis (TGA), X-ray diffraction (XRD) and Field Emission Scanning Electron Microscopy technique (FESEM). FTIR second derivative showed the presence of minor amounts of bound hemicellulose and relatively free of lignin compound. The crystallinity index of LLS-cellulose is higher than LLS-MCC, indicating higher crystallize size and thermal decomposition. FESEM image also showed that there is smooth surface of raw LLS after hot boiling extraction for 2 hours. Thus, this study revealed that the lignin and hemicelluloses can be removed efficiently by using hot water treatment. In addition, cellulose components produced from waste LLS could be used as precursors of other industrial applications.
\end{abstract}

(C) 2017 The Authors. Published by IASE. This is an open access article under the CC BY-NC-ND license (http://creativecommons.org/licenses/by-nc-nd/4.0/).

\section{Introduction}

Various crops are currently being studied for energy production and industrial applications. The choice on which lignocellulosic biomass is suitable for the targeted products depends on several factors such as its availability, carbohydrate composition and competition with food resources. Different grades of microcrystalline cellulose (MCC) could be obtained from agricultural residues depending on the source of plants and process involved (ElSakhawy and Hassan, 2007). Various sources of plant have been studies for isolation of cellulose which further can used to produce MCC and nanocrystal such as oil palm mass residue (Johar et al., 2012; Soom et al., 2009; Haafiz et al., 2013), jute (Jahan et al., 2011) banana plant waste (Elanthikkal et al., 2010), bagasse, rice straw (El-Sakhawy and

\footnotetext{
* Corresponding Author.

Email Address: ilham@um.edu.my (Z. Ilham)

https://doi.org/10.21833/ijaas.2017.03.009

2313-626X/C 2017 The Authors. Published by IASE.

This is an open access article under the CC BY-NC-ND license

(http://creativecommons.org/licenses/by-nc-nd/4.0/)
}

Hassan, 2007; Ilindra and Dhake, 2008; Nuruddin et al., 2011), wheat straw, corn stalks, dhaincha (Nuruddin et al., 2011), kenaf (Wang et al., 2010), alfa (Trache et al., 2014), cotton stalks (El-Sakhawy and Hassan, 2007), soybean hull (Merci et al., 2015), tomato peel (Jiang and Hsieh, 2015) and pineapple leaf (Cherian et al., 2011). Honda et al. (2002) even utilized waste sewage sludge as feedstock. The idea of extracting cellulose from unused agricultural residues or lignocellulosic waste is align with the current interest towards waste minimization and waste to wealth concept.

Production of cellulose from lignocellulosic biomass requires pretreatment step to remove undesired hemicelluloses and lignin which act as protective barrier to cellulose. Many studies have been reported on the removal of hemicelluloses and lignin by using alkaline solution such as $\mathrm{NaOH}$ and followed by bleaching (Elanthikkal et al., 2010). On the other hand, Nazir et al. (2013) employed a mixture of formic acid and hydrogen peroxide method. Cellulose in the plants material can be categorized into two forms, mainly known as crystalline and amorphous. Crystalline is the major constituent of cellulose in biomass while amorphous 
accounts relatively in small amount. In biocomposite and biomedical industries, cellulose with high crystallinity is more suitable to be applied due to its strength and high resistance. Next process involved after the isolation of microcrystalline cellulose (MCC) from the obtained cellulose requires a removal of amorphous regions. This is normally done by acid hydrolysis using $\mathrm{HCl}$ or $\mathrm{H}_{2} \mathrm{SO}_{4}$. The isolated cellulose and MCC can be further used as a source for nanocrystal production.

Leucaena leucocephala is abundance in coverage at most tropical regions of the world. The fact that this fast-growing plant could grow on marginal lands with minimum care had attracted attention for researchers to maximize its possible utilization. Some studies focused on using its biomass as livestock feed (Ahmed and Abdelati, 2009), paper production (Pandey and Kumar, 2013) and extraction of oil from LLS for cosmetic and pharmaceutical or conversion to biodiesel (Phoo et al., 2012). However, waste LLS, obtained as residues after extraction of oil are unused although it has a potential as a source of lignocellulosic material. The aim of the present paper is to extract the cellulose from waste LLS by using an environmental friendly method for removal of non-cellulosic biomass. Subsequently, the isolated cellulose will be converted into microcrystalline cellulose. The properties of prepared cellulose and MCC will be measured for its chemical composition, thermal stability, particles morphology and crystallinity index in order to check its potential for use as precursors of other industrial applications.

\section{Materials and methods}

\subsection{Materials}

Waste Leucaena leucocephala seeds (LLS) used in this study were obtained from the residues after oil extraction for conversion to biodiesel in Biomass Energy Laboratory at Institute of Biological Sciences, Faculty of Science, University of Malaya, Malaysia. The LLS were initially collected at Selayang Baru, Selangor, Malaysia in December 2014. The LLS obtained were ground and dried at $105^{\circ} \mathrm{C}$ for 24 hours before extracted for its oil following an established procedure (Lubes and Zakaria, 2009). All analytical grade chemicals were purchased from Merck, Malaysia and were used for cellulose and microcellulose isolation.

\subsection{Removal of primary and secondary metabolites from LLS}

Removal of primary and secondary metabolites was done according to Duarte et al. (2011) with some modifications. The LLS seed waste were grounded to powder and suspended in distilled water followed by extraction with boiling water under reflux. Extraction was carried out at $95-100^{\circ} \mathrm{C}$ and the heating was 2 hours. After filtration aqueous extract was discarded and the insoluble residues were collected and dried in oven at $60^{\circ} \mathrm{C}$ and stored until further isolation of cellulose step is employed.

\subsection{Isolation of cellulose from the LLS}

The isolation method was adapted based on original procedures described by Sun et al. (2004). The dried insoluble residues of LLS were suspended in a mixture of $80 \%$ of acetic acid and $65 \%$ of nitric acid solution. The solution was heated at $90^{\circ} \mathrm{C}$ for 1 hour. Then, the solution was cooled at room temperature and filtered. The insoluble whitish residue was washed repeatedly with distilled water until the $\mathrm{pH}$ of the washing distillate water became pH 5-6. After that the residue (cellulose) was dried at room temperature. The mass of dried cellulose was measured.

\subsection{Preparation of microcrystalline cellulose (MCC)}

The acid hydrolysis of LLS-cellulose was conducted according to a classic method (Battista, 1950). Prepared cellulose was hydrolysed with $2.5 \mathrm{~N}$ hydrochloric acid under reflux for about 1 hour at $90^{\circ} \mathrm{C}-100^{\circ} \mathrm{C}$ and the ratio of cellulose over liquor was $1: 20$. The hydrolysed cellulose was filtered and washed repeatedly with distilled water until it is free from acid. The solid residue (MCC) was dried in an oven at $105^{\circ} \mathrm{C}$.

\section{Characterization of sample}

\subsection{Fourier transforms infrared spectroscopy (FTIR)}

Fourier transform infrared spectroscopy was recorded using a Perkin-Elmer Spectrum 100 IR spectrophotometer. Ultrathin pellets were prepared by mixing $2 \mathrm{mg}$ of each samples (Leucaena Leucocephala seeds (LLS), cellulose and MCC) with potassium bromide (KBr) powder. ID Spectra of all samples were recorded in the range of $4000-450 \mathrm{~cm}^{-}$ 1 to analyse the different in functional groups present. The second derivative IR spectra were obtained by using Savitzky-Golay filter through 13 point smoothing.

\subsection{Thermogravimetric analysis (TGA)}

A Netzsch Thermogravimetric analyzer (TG209 F3 Tarsus model) was used to study the thermal behaviour of the samples. Each sample $(10.0 \pm 1.0$ $\mathrm{mg}$ ) were analysed from $30-900{ }^{\circ} \mathrm{C}$ at a rate of $10^{\circ} \mathrm{C} / \mathrm{min}$ under a nitrogen atmosphere, with a gas flow of $80 \mathrm{~cm}^{3} / \mathrm{min}$. 


\subsection{Field emission scanning electron microscopy (FESEM)}

Field emission scanning electron microscopy was carried out using a JEOL JSM-7600F. A small amount of the LLS, cellulose and MCC were coated with gold using a vacuum sputter coater (model SCD 005). The FESEM micrographs were obtained to study the surface morphology and crystallite size of each sample.

\subsection{X-ray diffraction technique (XRD)}

Diffraction patterns of the samples were performed with an X-ray diffractometer (X'Pert PRO MD PANalytical). XRD pattern were recorder in the $2 \theta$ range of $10-90^{\circ}$ with an automated $X$-ray using CuK $\alpha$ radiation as the beam source $(\lambda=1.5418 \AA)$ and a scan rate of $1.5^{\circ} \mathrm{min}^{-1}$. The operating voltage is $35 \mathrm{kV}$ and tube current equal to $30 \mathrm{~mA}$. The crystalline index (CI) of the samples was determined according to the following equation:

$C I(\%)=\frac{I_{002}-I_{A M}}{I_{002}}$

where, $\mathrm{CI}$ is the crystallinity index, $\mathrm{I}_{002}$ is the maximum intensity at $2 \theta$ of 22.6 and $I_{A M}$ is the intensity of the amorphous measured at about $2 \theta=$ 18-19.

\section{Results and discussion}

The purpose of treatment using hot boiling water prior to acetic acid-nitric acid extraction is to remove any primary metabolites such as soluble and insoluble polysaccharides, protein, and acid soluble lignin from the LLS. Several secondary metabolites such as amino acids, tannins and saponin are expected to be removed from LLS as well. This treatment facilitates the extraction of cellulose. The bleaching process using sodium chlorite treatment was not carry out due to acetic acid-nitric acid treatment that has been whitened and isolated the cellulose concurrently. This cellulose extraction procedure is expected to be more environmental friendly, which only used water during the pretreatment step. The yields of LLS-cellulose extracted from LLS were 33\% (dry mass). This yield was higher compared to the cellulose yield found in the mango seeds, which was 29\% (Henrique et al., 2013). After purification process, the percent yield of LLS-MCC obtained from LLS-cellulose was 71\% (dry mass).

\subsection{FTIR spectral analysis}

The IR spectra of the LLS, LLS-treated, LLScellulose and LLS-MCC are shown in Fig. 1. The spectra of LLS-cellulose and LLS-MCC showed almost identical IR absorption peaks, indicating that their functional groups were not distinctively different. However the prominent peak at $1732 \mathrm{~cm}^{-1}-1745 \mathrm{~cm}^{-}$
1 in the spectrum LLS, LLS-treated and LLS-cellulose can be associated to the present of lignin and hemicellulose. According to several authors, this peak indicates either acetyl or uronic ester groups in hemicellulose or the ester linkage of carboxylic group of the ferulic and p-coumaric acids lignin (Johar et al., 2012; Elanthikkal et al., 2010; Chirayil et al., 2014; Normand et al., 2014). Almost no similar peak is present in the FTIR spectra of the LLS-MCC. The peaks at $1242 \mathrm{~cm}^{-1}$ and $1241 \mathrm{~cm}^{-1}$ of LLS and LLS-treated were associated with the C-O out of plane stretching vibration of the aryl group in lignin (Mandal and Chakrabarty, 2011). The appearance of a peak at around 1337 in all samples is related to the bending vibration of the $\mathrm{C}-\mathrm{H}$ and $\mathrm{C}-\mathrm{O}$ bonds in the cyclic ring of sugar moiety.

The absorption band at $1430 \mathrm{~cm}^{-1}$ and $898 \mathrm{~cm}^{-1}$ were observed in the LLS-cellulose and LLS-MCC. The band associated to a symmetric $\mathrm{CH}_{2}$ bending vibration at $1430 \mathrm{~cm}^{-1}$ is called as the crystallinity band and increase in its intensity demonstrates higher degree of crystallinity (Trache et al., 2014; Kalita et al., 2013; Shankar and Rhim, 2016). On the other hand, the peak at $897 \mathrm{~cm}^{-1}$ is originated from $\beta$-glycosidic linkages between glucose units in cellulose (Sun et al., 2004) and the intensity will decrease when the crystallinity of the sample increased (Soom et al., 2009). FTIR spectrum of LLSMCC showed a decrease in intensity for both the crystallinity band compared to that of MCC, which suggested that the crystallinity index cellulose fibrils decreased during hydrolysis process and this observation will be confirmed by XRD analysis. Higher crystallinity in LLS-cellulose can be further confirmed by the increase in intensity of the absorption band from $2916 \mathrm{~cm}^{-1}$ to $2917 \mathrm{~cm}^{-1}$ which is associated with C-H stretching (Kalita et al., 2013). The peak range of $3306-3349 \mathrm{~cm}^{-1}$ of all samples was associated with the intermolecular and intramolecular $\mathrm{O}-\mathrm{H}$ stretching vibration band. The peaks at $1060 \mathrm{~cm}^{-1}$ and $1639 \mathrm{~cm}^{-1}$ were detected in all sample was due to the $\mathrm{C}-\mathrm{O}-\mathrm{C}$ pyranose ring skeletal vibration and $\mathrm{OH}$ bending of absorbed water (Mandal and Chakrabarty, 2011; Kalita et al., 2013). In addition, the peak at $1112 \mathrm{~cm}^{-1}$ is known as the ring breathing band corresponds to $\mathrm{C}-\mathrm{C}$.

\subsection{Second derivative IR spectral analysis}

Second derivative IR spectra used in this study is to enhance spectral resolution and can improved some overlapped absorption peaks. Studies from He et al. (2007) showed the second derivative IR spectra lies in the range $3600-3200 \mathrm{~cm}^{-1}$. In this study, the second derivative FTIR is in the region 1800-1000 and $800-450 \mathrm{~cm}^{-1}$. The spectra of LLS-cellulose and LLS-MCC showed in Fig. 2 had almost the same profile and band intensity. The second derivative FTIR showed the band at $1511 \mathrm{~cm}^{-1}$, assigned to the aromatic $\mathrm{C}=\mathrm{C}$ vibration in lignin is reduced significantly in LLS-cellulose and LLS-MCC. The peaks at $1701-1737 \mathrm{~cm}^{-1}$ that attributes to $\mathrm{C}=0$ stretching of hemicellulose and lignin were not 
present. The predominant peaks at 1432 and 1373 $\mathrm{cm}^{-1}$ were associated with bending vibration of $\mathrm{CH} 2$ and $\mathrm{CH}$ attributed to the characteristic of cellulose. Further, the peak at 1337 and $1317 \mathrm{~cm}^{-1}$ indicate C$\mathrm{OH}$ plane bending and $\mathrm{CH} 2$ wagging (Bian et al.,
2012). Spectral analysis using second derivative clearly showed minor differences in the spectrum thus, suitable to identify the chemical constituents and to compare the effectiveness of treatment.

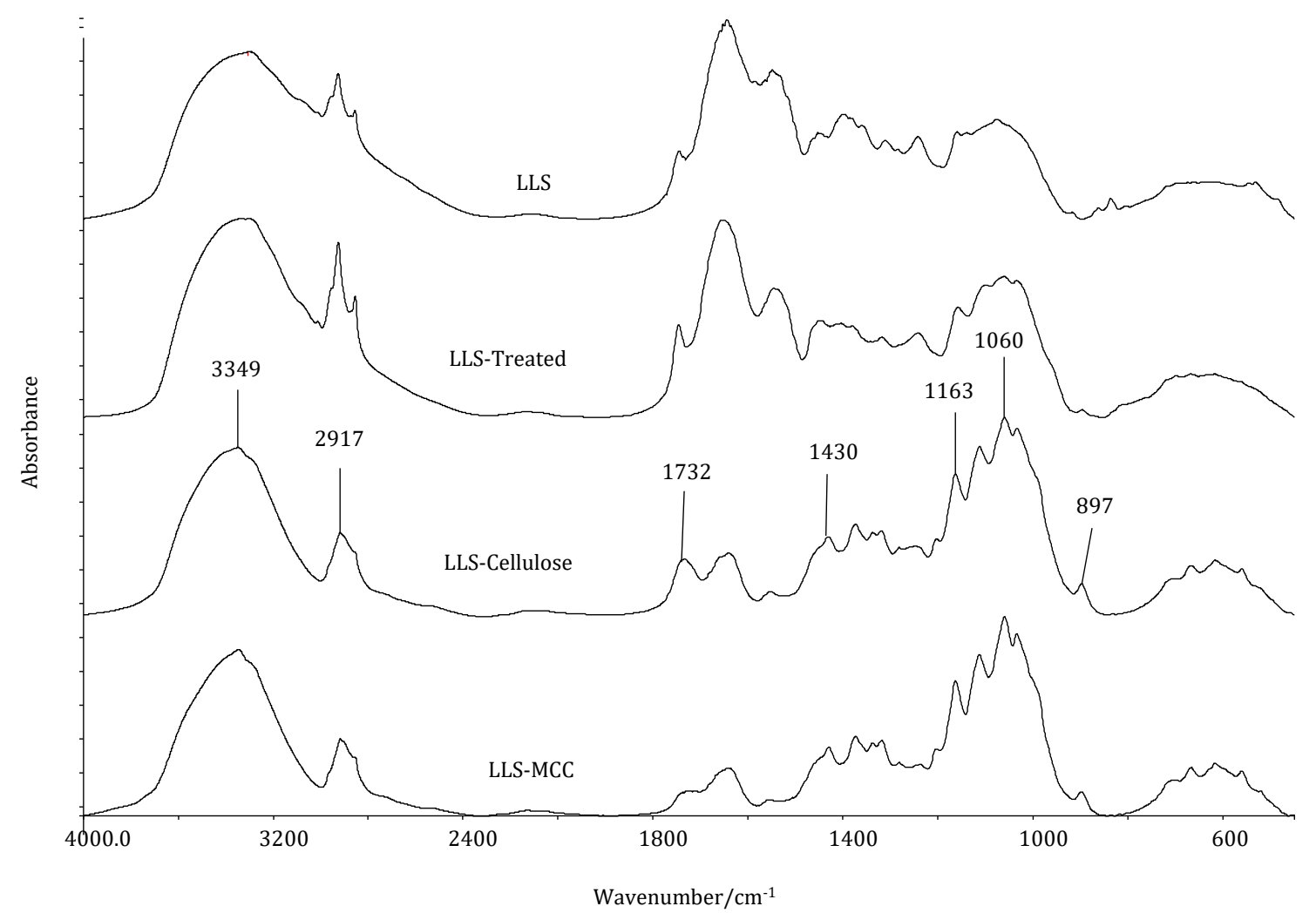

Fig. 1: IR spectra of the LLS, LLS-Treated, LLS-cellulose and LLS-MCC

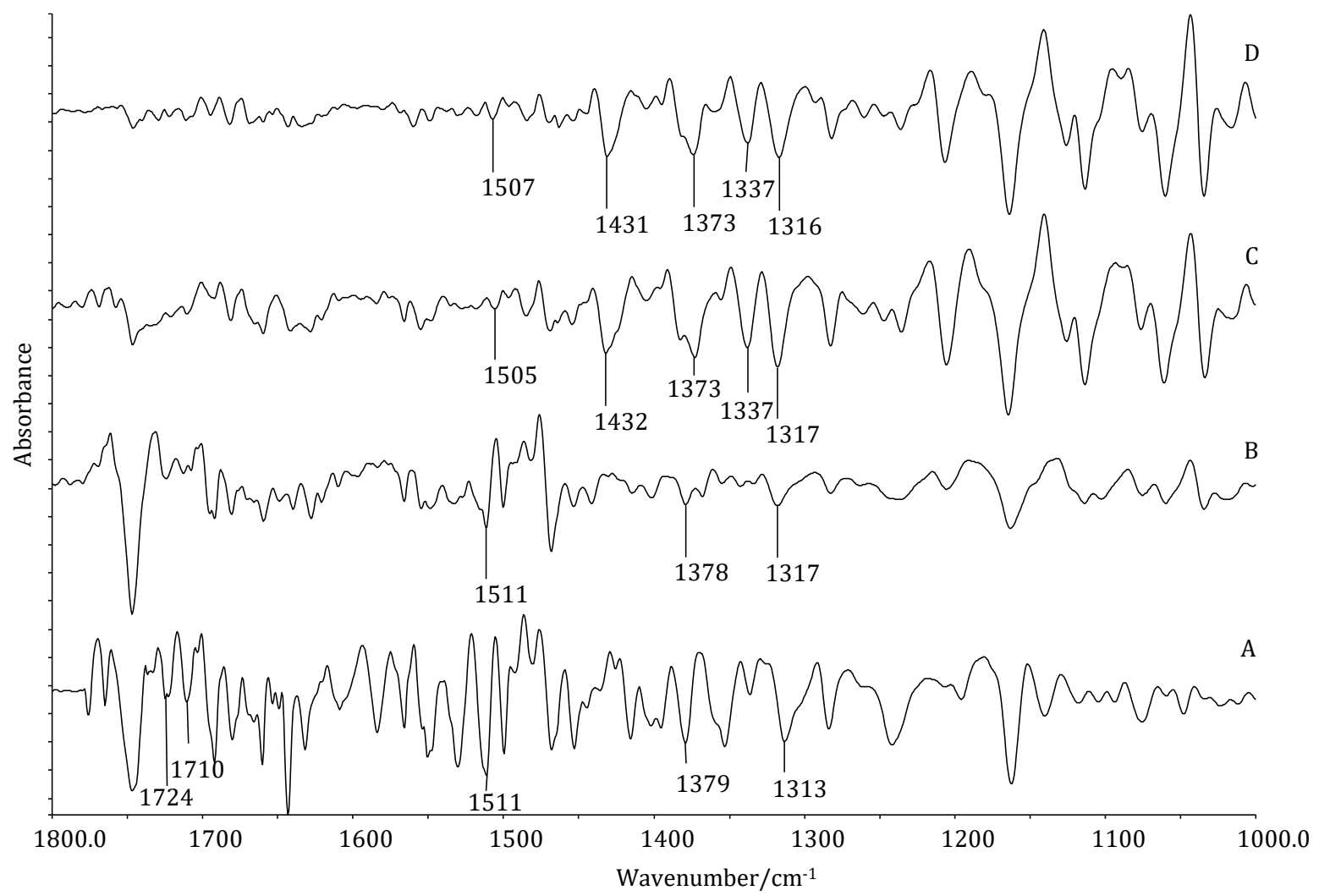

Fig. 2: Second derivative IR spectra in the range of 1800-1000 of the (A) LLS (B) LLS-Treated(C) LLS-cellulose (D) LLS-MCC 


\subsection{X-ray diffraction}

Biomass crystallinity estimation is very important to give the researcher information about the digestibility of the sample (Park et al., 2010). At present, there are four techniques that can be used to determine the crystallinity index (CI) of the materials which are XRD, solid state 13C NMR, infrared spectroscopy and Raman spectroscopy. XRD is the most widely been applied to obtained the CI even though there are limitations mentioned by several authors (Park et al., 2010; Poletto et al., 2014).

Image based on Fig. 3, indicates the presence of cellulose type 1 , with absence of the doublet located at main diffraction peak $\left(22.6^{\circ}\right)$. Qualitatively the peak intensity of LLS-cellulose appeared higher than that LLS-MCC and LLS, shows that the LLS-cellulose was more crystalline than others. CI of the LLScellulose was reduced after converted to microfibrils (LLS-MCC) from $67 \%$ to $57 \%$ respectively. Thus, indicating that LLS-cellulose structure more rigid than LLS-MCC. The high crystallinity material is suitable to be used in biocomposite processing. Cellulose is composed of the crystalline and noncrystalline (amorphous) parts. During conversion to MCC by acid hydrolysis, acid hydrolysis tends to reduce the crystallinity of the materials (Sun et al., 2004).

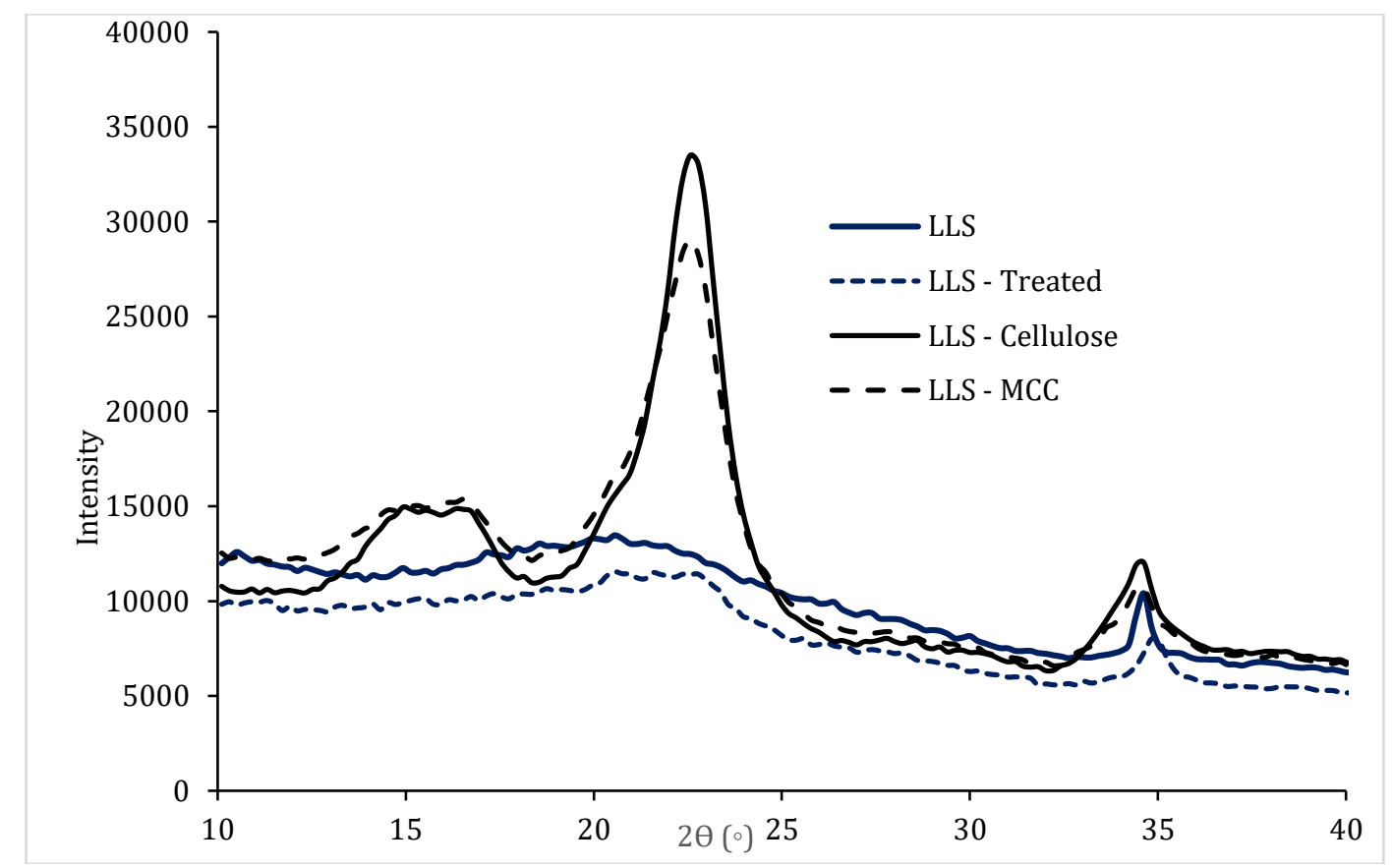

Fig. 3: X-ray diffraction patterns of the LLS, LLS-Treated, LLS-Cellulose and LLS-MCC

\subsection{Scanning electron microscopy}

Fig. 4 shows the FESEM images of raw LLS and treated LLS. The image of raw LLS show smooth surfaces with compact fibril packing, which typically contains hemicellulose, cellulose, lignin other elements (inorganic components). Relative composition was obtained by EDX data, revealing the highest element in the LLS structure is $\mathrm{C}$ followed by 0 . Other elements present in minor percentage are $\mathrm{K}, \mathrm{Na}, \mathrm{Mg} \mathrm{S}, \mathrm{Ca}$ and $\mathrm{Mg}$. After treated with boiling water under reflux for 2 hours, the image show there is changes in the surface of raw LLS.

The FESEM micrograph of LLS-cellulose and LLSMCC are presented in Fig. 5. The surface morphology of LLS-cellulose and LLS-MCC obtained were comprised of individual fibres and a few bundle form. It is observed that there is more individual fibre obtained in LLS-MCC due to destruction of fibre bundles during acid hydrolysis. The diameters of individual fibre of LLS-MCC prepared based acid hydrolysis was around 5-10 $\mu \mathrm{m}$, which is similar or lower than other plant fibres reported by others
(Jahan et al., 2011; Nuruddin et al., 2011; Wang et al., 2010).

\subsection{Thermogravimetric analysis}

Data from thermogravimetric analysis (TGA) is very useful to evaluate the thermal stability of natural fibres in order to be used in biocomposite processing. The mixing process of biocomposite (polymer matrix and natural fibres) is occurred at high temperature, which is above than $200^{\circ} \mathrm{C}$, thus degradation profile of the lignocellulosic materials must be identified. Figs. 6 and 7 showed the TGA and DTG behaviours.

Initial stage of all samples known as drying stage was occurred at temperature ranging from 29$120^{\circ} \mathrm{C}$. Many studies reported that at the initial stage the weight loss was due to the water evaporation in the samples (Johar et al., 2012; Trache et al., 2014; Mandal and Chakrabarty, 2011). The rate of temperature for water evaporation depends on the original moisture content of the sample. The LLS shows 3 important degradation steps which are referred to the degradation hemicellulose, cellulose 
and degradation of lignin. It was reported by Yang et al. (2007) that the degradation temperature for hemicellulose and cellulose were occurred at 220 $315^{\circ} \mathrm{C}$ and $315-400^{\circ} \mathrm{C}$ respectively. The degradation of lignin slowly occurred at temperature ranging from ambient to $900^{\circ} \mathrm{C}$, thus the decomposition is overlapped in between hemicellulose and cellulose. A similar profile was reported for fibres from wood (Park et al., 2010).
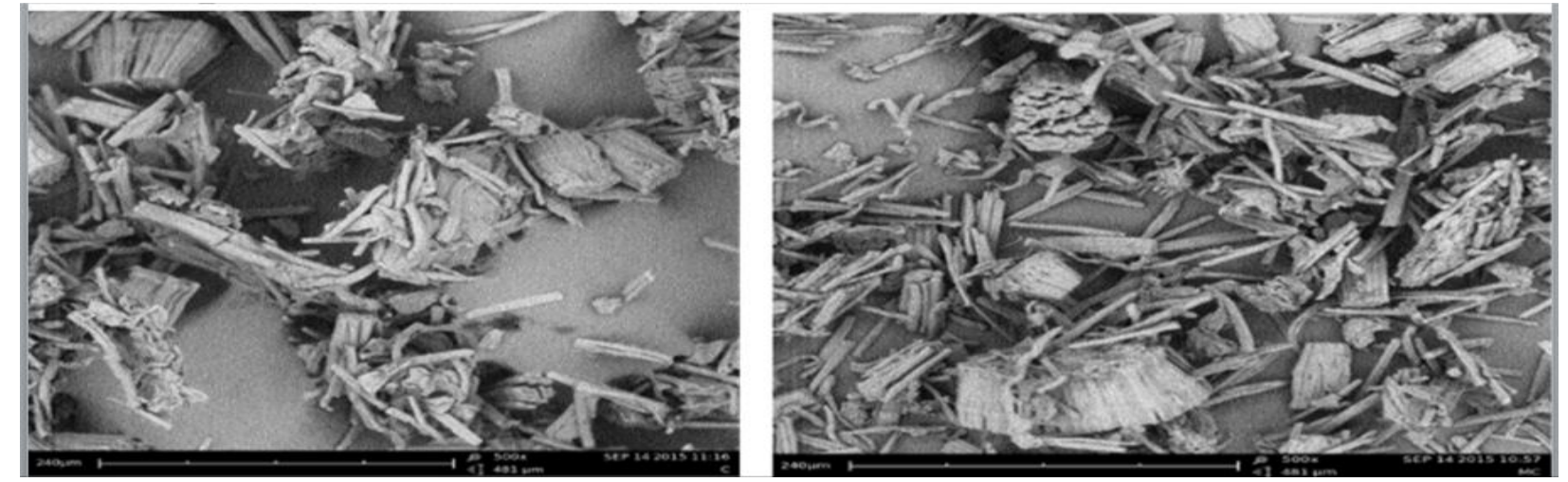

Fig. 4: FESEM micrographs of raw LLS (left) and treated LLS (right)
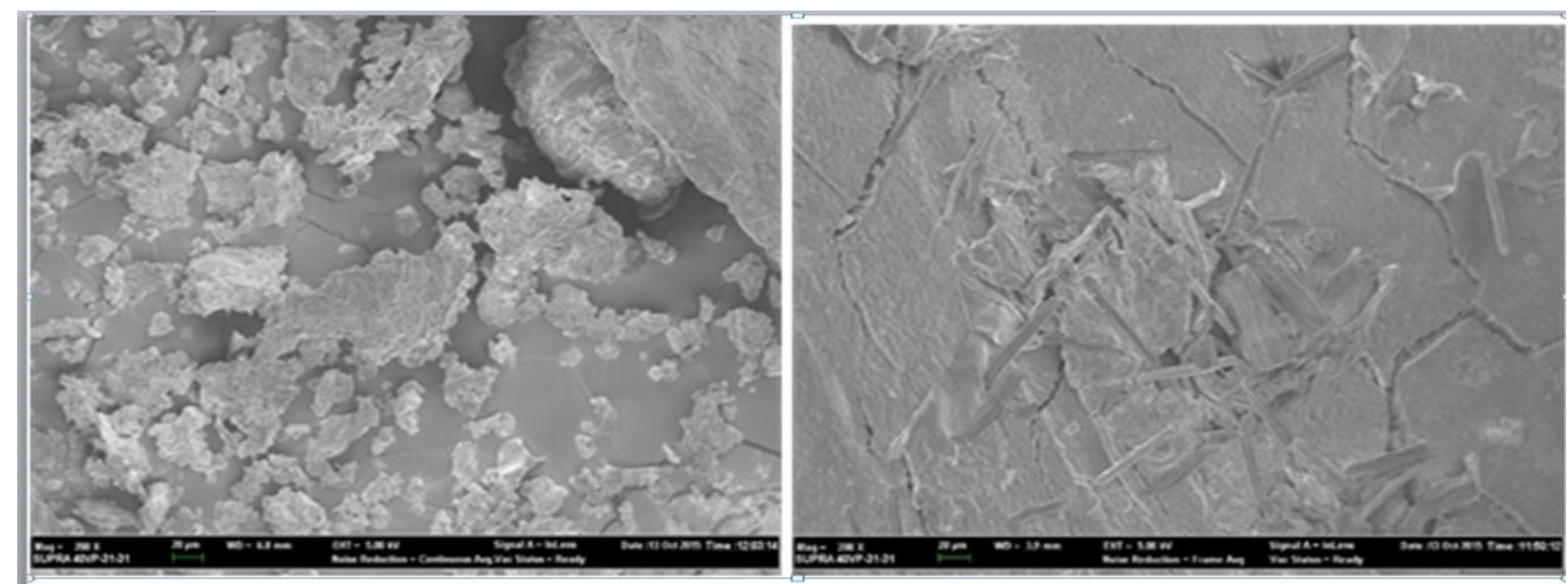

Fig. 5: FESEM micrograph of LLS-Cellulose (left) and LLS-MCC (right)

\subsection{Advantages of using cellulose from lignocellulosic waste}

Previously, various agricultural residues or could be termed as lignocellulosic waste have been used for extraction of cellulose (Johar et al., 2012; Honda et al., 2002). However, only in this study that waste Leucaena leucocephala seeds from biodiesel production is first used. Leucaena leucocephala is a fast-growing species, abundant, non-food source and could grow on nutrient-deficit lands. It could serve as a potential cheap feedstock for cellulose. Utilization of lignocellulosic waste such as those studied before and the new one used in this study is strongly aligned with the current interest towards waste minimization and waste to wealth concept.
The decomposition peaks where the maximum mass loss occurred for LLS, LLS-treated, LLS cellulose and LLS-MCC were at 214, 304, 324 and $304^{\circ} \mathrm{C}$ respectively. Degradation peak of LLScellulose is higher than LLS-MCC might be due to the different of the degree of crystallinity. While degradation pattern for LLS-Cellulose and LLS-MCC obtained are found to be similar to that jute and oil palm biomass (Haafiz et al., 2013; Jahan et al., 2011; Fahma et al., 2010). 


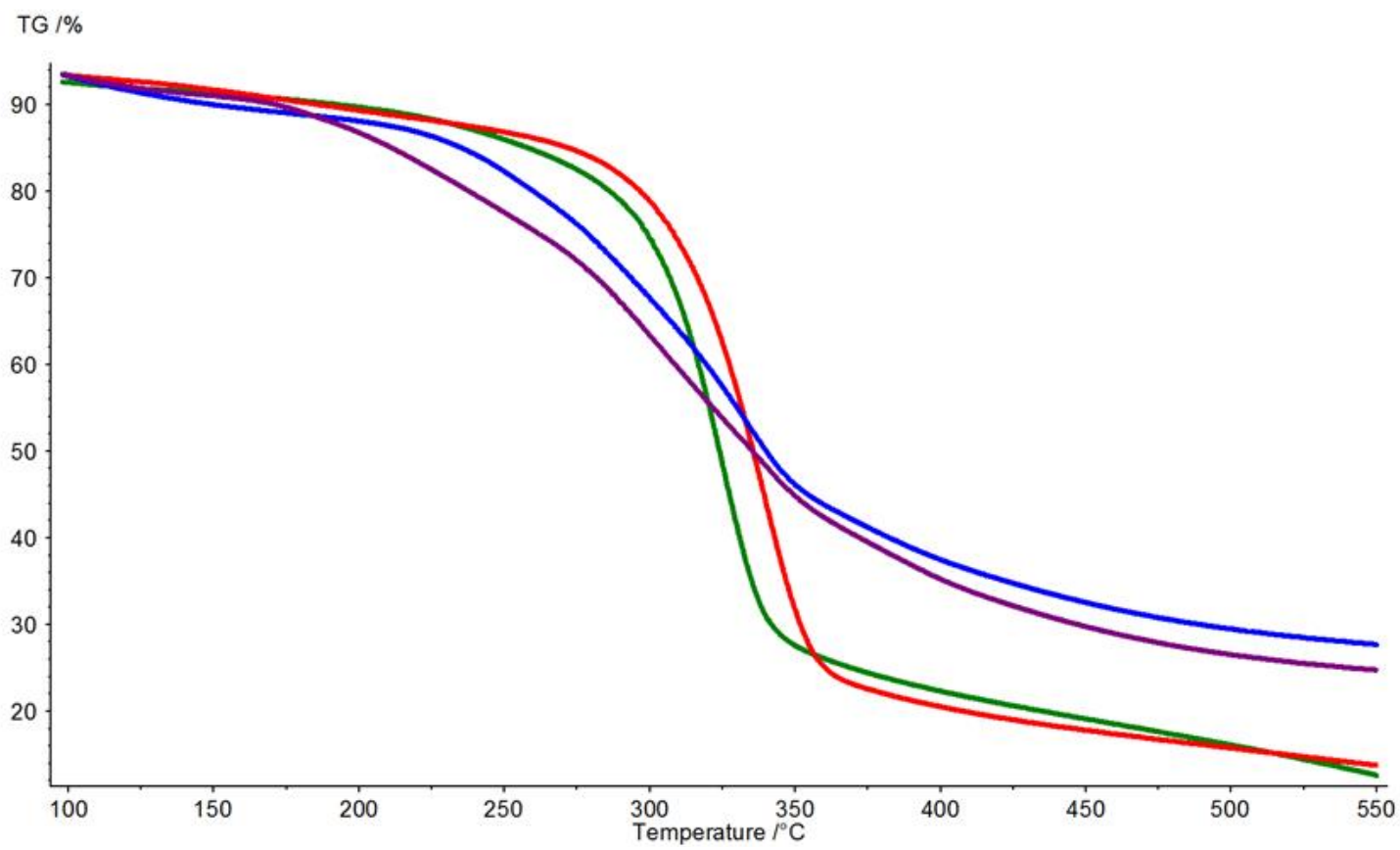

Fig. 6: TGA behaviour of (A) LLS (B) LLS-Treated (C) LLS-Cellulose (D) LLS-MMC

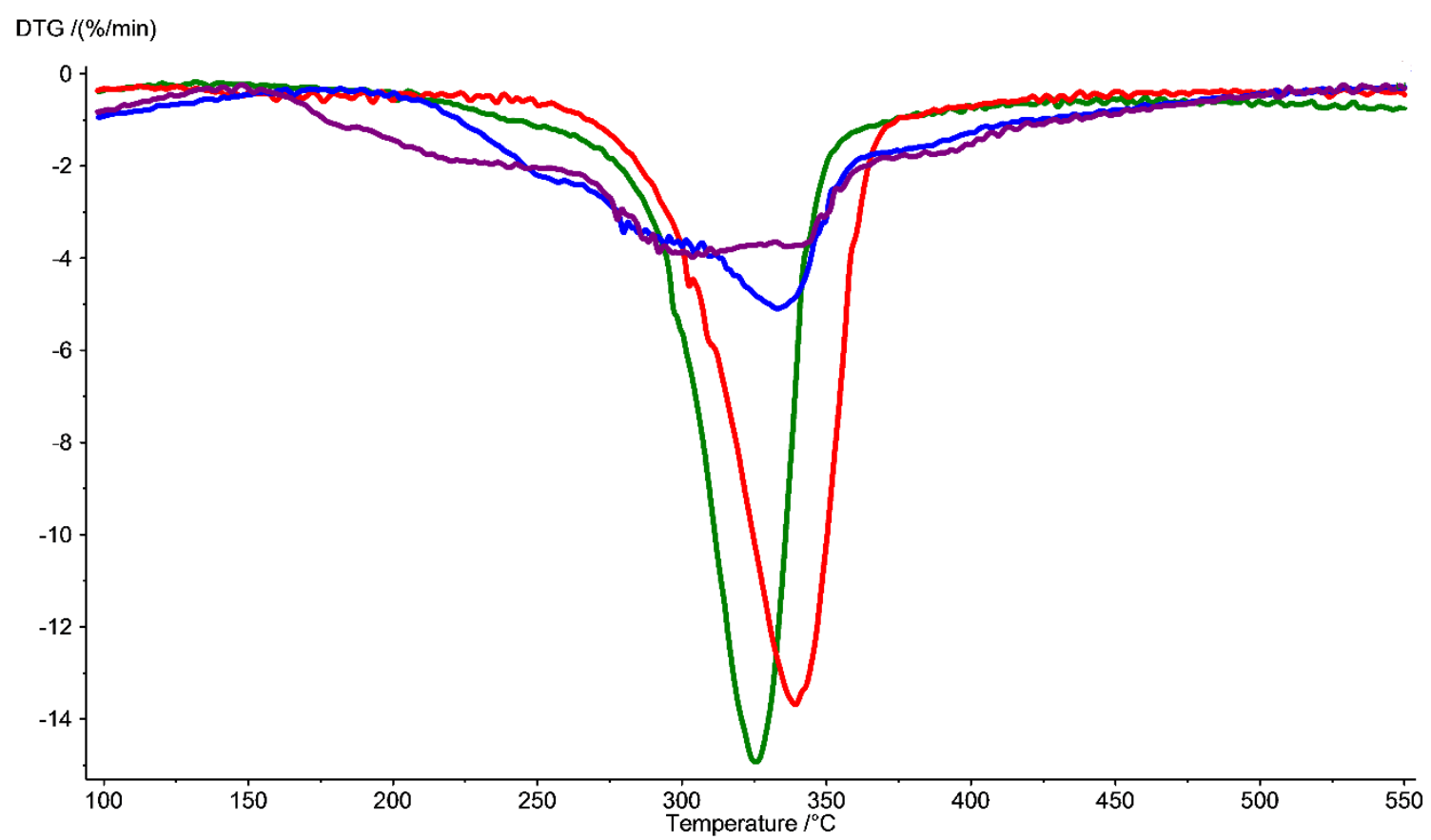

Fig. 7: DTG behaviour of (A) LLS (B) LLS-Treated (C) LLS-Cellulose (D) LLS-MMC

\section{Acknowledgment}

The authors would like to thank University of Malaya for continuous support and the research funding PG101-2015A and RP004B-13BIO. Special appreciation goes to the assistant science officers, Norizan Moez and Joohari Ismail.

\section{References}

Ahmed ME and Abdelati KA (2009). Chemical composition and amino acids profile of Leucaena leucocephala seeds. International Journal of Poultry Science, 8(10): 966-970.

Battista OA (1950). Hydrolysis and crystallization of cellulose. Industrial and Engineering Chemistry, 42(3): 502-507.
Bian J, Peng F, Peng XP, Peng P, Xu F, and Sun RC (2012). Acetic acid enhanced purification of crude cellulose from sugarcane bagasse: Structural and morphological characterization. BioResources, 7(4): 4626-4639.

Cherian BM, Leão AL, Souza SFD, Costa LMM, Olyveira GMD, Kottaisamy M, Nagarajan ER, and Thomas S (2011). Cellulose nanocomposites with nanofibres isolated from pineapple leaf fibers for medical applications. Carbohydrate Polymers, 86(4):1790-1798.

Chirayil CJ, Joy J, Mathew L, Mozetic M, Koetz J, and Thomas S (2014). Isolation and characterization of cellulose nanofibrils from Helicteres isora plant. Industrial Crops and Products, 59: 27-34.

Duarte GV, Ramarao BV, Amidon TE, and Ferreira PT (2011). Effect of hot water extraction on hardwood kraft pulp fibers (Acer saccharum, Sugar Maple). Industrial and Engineering Chemistry Research, 50(17): 9949-9959. 
Elanthikkal S, Gopalakrishnapanicker U, Varghese S, and Guthrie JT (2010). Cellulose microfibres produced from banana plant wastes: Isolation and characterization. Carbohydrate Polymers, 80(3): 852-859.

El-Sakhawy M and Hassan ML (2007). Physical and mechanical properties of microcrystalline cellulose prepared from agricultural residues. Carbohydrate Polymers, 67(1): 1-10.

Fahma F, Iwamoto S, Hori N, Iwata T, and Takemura A (2010). Isolation, preparation, and characterization of nanofibers from oil palm empty-fruit-bunch (OPEFB). Cellulose, 17(5): 977-985.

Haafiz MKM, Eichhorn SJ, Hassan A, and Jawaid M (2013). Isolation and characterization of microcrystalline cellulose from oil palm biomass residue. Carbohydrate Polymers, 93(2): 628-634.

He J, Tang Y, and Wang SY (2007). Differences in morphological characteristics of bamboo fibres and other natural cellulose fibres: Studies on x-ray diffraction, solid state ${ }^{13} \mathrm{C}-\mathrm{CP} / \mathrm{MAS}$ NMR, and second derivative FTIR spectroscopy data. Iranian Polymer Journal, 16(12): 807-818.

Henrique MA, Silvério HA, Neto WPF, and Pasquini D (2013). Valorization of an agro-industrial waste, mango seed, by the extraction and characterization of its cellulose nanocrystals. Journal of Environmental Management, 121: 202-209.

Honda S, Miyata N, and Iwahori K (2002). Recovery of biomass cellulose from waste sewage sludge. Journal of Material Cycles and Waste Management, 4(1): 46-50.

Ilindra A and Dhake JD (2008). Microcrystalline cellulose from bagasse and rice straw. Indian Journal of Chemical Technology, 15(5): 497-499.

Jahan MS, Saeed A, He Z, and Ni Y (2011). Jute as raw material for the preparation of microcrystalline cellulose. Cellulose, 18(2): 451-459.

Jiang F and Hsieh YL (2015). Cellulose nanocrystal isolation from tomato peels and assembled nanofibers. Carbohydrate Polymers, 122: 60-68.

Johar N, Ahmad I, and Dufresne A (2012). Extraction, preparation and characterization of cellulose fibres and nanocrystals from rice husk. Industrial Crops and Products, 37(1): 93-99.

Kalita RD, Nath Y, Ochubiojo ME, and Buragohain AK (2013). Extraction and characterization of microcrystalline cellulose from fodder grass; Setaria glauca (L) P. Beauv, and its potential as a drug delivery vehicle for isoniazid, a first line antituberculosis drug. Colloids and Surfaces B: Biointerfaces, 108: 85-89.

Lubes ZIZ and Zakaria M (2009). Analysis of parameters for fatty acid methyl esters production from refined palm oil for use as biodiesel in the single- and two-stage processes. Malaysian Journal of Biochemistry and Molecular Biology, 17(1): 5-9.

Mandal A and Chakrabarty D (2011). Isolation of nanocellulose from waste sugarcane bagasse (SCB) and its characterization. Carbohydrate Polymers, 86(3): 1291-1299.
Merci A, Urbano A, Grossmann MVE, Tischer CA, and Mali S (2015). Properties of microcrystalline cellulose extracted from soybean hulls by reactive extrusion. Food Research International, 73: 38-43.

Nazir MS, Wahjoedi BA, Yussof AW, and Abdullah MA (2013). Ecofriendly extraction and characterization of cellulose from oil palm empty fruit bunches. BioResources, 8(2): 2161-2172.

Normand ML, Moriana R, and Ek M (2014). Isolation and characterization of cellulose nanocrystals from spruce bark in a biorefinery perspective. Carbohydrate Polymers, 111: 979987.

Nuruddin M, Chowdhury A, Haque SA, Rahman M, Farhad SF, Jahan MS, and Quaiyyum A (2011). Extraction and characterization of cellulose microfibrils from agricultural wastes in an integrated biorefinery initiative. Cellulose Chemistry Technology, 45(5-6): 347-354.

Pandey VC and Kumar A (2013). Leucaena leucocephala: an underutilized plant for pulp and paper production. Genetic Resources and Crop Evolution, 60(3): 1165-1171.

Park S, Baker JO, Himmel ME, Parilla PA, and Johson DK (2010). Cellulose crystallinity index: measurement techniques and their impact on interpreting cellulase performance. Biotechnology for Biofuels, 3(1): 1-10.

Phoo ZWMM, Ilham Z, Goembira F, Razon L, and Saka S (2012). Physico-chemical properties of biodiesel from various feedstocks. In: Yao T (Eds.), Green Energy and Technology: 113-121. Springer, Japan.

Poletto M, Júnior HLO, and Zattera AJ (2014). Native cellulose: Structure, characterization and thermal properties. Materials (Basel), 7(9): 6105-6119.

Shankar S and Rhim JW (2016). Preparation of nanocellulose from micro-crystalline cellulose: The effect on the performance and properties of agar-based composite films. Carbohydrate Polymers, 135: 18-26.

Soom RM, Aziz AA, Hassan WHW, and Top AGM (2009). Solidstate characteristics of microcrystalline cellulose from oil palm empty fruit bunch fibre. Journal of Oil Palm Research, 21: 613-620.

Sun JX, Sun XF, Zhao H, and Sun RC (2004). Isolation and characterization of cellulose from sugarcane bagasse. Polymer Degradation and Stability, 84(2): 331-339.

Trache D, Donnot A, Khimeche K, Benelmir R, and Brosse N (2014). Physico-chemical properties and thermal stability of microcrystalline cellulose isolated from Alfa fibres. Carbohydrate Polymers, 104: 223-230.

Wang D, Shang SB, Song ZQ, and Lee MK (2010). Evaluation of microcrystalline cellulose prepared from kenaf fibers. Journal of Industrial and Engineering Chemistry, 16(1): 152-156.

Yang H, Yan R, Chen H, Lee DH, and Zheng C (2007). Characteristics of hemicellulose, cellulose and lignin pyrolysis. Fuel, 86(12): 1781-1788. 